\title{
Compreendendo a Formação Matemática de Futuros Pedagogos por meio de Narrativas
}

\section{Understanding the Mathematics Training of Futures Pedagogues through Narratives}

\author{
Rejane Siqueira Julio* \\ ORCID iD 0000-0002-3248-800X \\ Guilherme Henrique Gomes da Silva** \\ ORCID iD 0000-0002-4166-2663
}

\begin{abstract}
Resumo
Este artigo tem como tema a formação matemática de futuros pedagogos. Seu objetivo é analisar narrativas escritas e orais produzidas por estudantes do curso de Pedagogia de uma Universidade Federal localizada no sul de Minas Gerais. Consideramos que a formação matemática se inicia antes do ingresso na universidade e, nesse sentido, é importante conhecê-la para contribuir no processo de formação destes estudantes. No decorrer da análise destas narrativas, foram construídas as seguintes categorias: visão geral da relação com a Matemática, postura dos professores, uso da Matemática na vida, modo de lidar com os conteúdos, conteúdo matemático mais citado e ênfase na alfabetização. Adicionado a isso, discutimos a participação dos conteúdos específicos, como é o caso da Matemática, nos cursos de Pedagogia. As discussões levantadas neste trabalho convergem para o papel do formador de pedagogos quando este se depara com pouco tempo para abordar conteúdos e metodologias da área de Educação Matemática e com as dificuldades trazidas por estudantes de Pedagogia desde a Educação Básica. Como perspectiva de formação, destacamos o cuidado com as microagressões relacionadas ao conteúdo matemático e a produção de significados no ensino e aprendizagem da Matemática.
\end{abstract}

Palavras-chave: Educação Superior. Educação Matemática. Currículo. Formação Matemática de Pedagogos. Narrativas.

\begin{abstract}
This paper addresses the mathematics training of prospective elementary teachers. It aims to analyze written and oral narratives produced by students from a Pedagogy program of a Brazilian Federal University. We take into account that the mathematical training of these students has started before the access to higher education. Thus, we consider it is important to understand this previous knowledge in order to contribute to these students' training process. During the narratives analysis, we built the following themes: general conception about mathematics; teacher posture; the use of mathematics in everyday practices; ways to deal with mathematical

\footnotetext{
* Doutora em Educação pela Universidade Estadual de Campinas (UNICAMP). Docente do Instituto de Ciências Exatas e do Programa de Pós-Graduação em Educação da Universidade Federal de Alfenas (UNIFAL), Alfenas, Minas Gerais, Brasil. Endereço para correspondência: Rua Gabriel Monteiro da Silva, 700, sala E207L, Centro, Alfenas, Minas Gerais, Brasil, CEP: 37130-001. E-mail: rejane.julio@ unifal-mg.edu.br.

** Doutor em Educação Matemática pela Universidade Estadual Paulista "Júlio de Mesquita Filho" (UNESP), Rio Claro, São Paulo. Docente do Instituto de Ciências Exatas e do Programa de Pós-Graduação em Educação da Universidade Federal de Alfenas (UNIFAL), Alfenas, Minas Gerais, Brasil. Endereço para correspondência: Rua Gabriel Monteiro da Silva, 700, sala E207J, Centro, Alfenas, Minas Gerais, Brasil, CEP: 37130-001. Email: guilherme.silva@unifal-mg.edu.br.
} 
contents; mathematical content mostly quoted; and emphasis on literacy. In addition, we discuss in this paper specifics mathematics contents from Pedagogy programs. The discussions converge to the role of teacher trainer when she/he is faced with the lack of time to address contents and methodologies of mathematics education and with the difficulties brought by her/him students since their basic schooling. Considering a training perspective, we emphasize the care with microaggressions related to mathematics contents and the meaning production related to mathematics teaching and learning.

Keywords: Higher Education. Mathematics Education. Curriculum. Mathematical Training of Elementary Teacher. Narratives.

\section{Introdução}

Atualmente, no Brasil, os cursos de graduação em Pedagogia têm se dedicado à formação inicial do professor para o exercício da docência no Ensino Infantil, nos Anos Iniciais do Ensino Fundamental e também em cursos de Educação Profissional. Além disso, estes cursos também preparam o futuro professor para a área de serviços e apoio escolar e para outras áreas em que sejam previstos conhecimentos pedagógicos (BRASIL, 2005).

Dessa forma, existem muitas possibilidades de atuação profissional para um pedagogo. Como docentes na Educação Infantil e nos Anos Iniciais do Ensino Fundamental, os pedagogos devem ensinar, de uma forma interdisciplinar e adequada às diferentes fases do desenvolvimento humano, conteúdos relacionados a diversas áreas, dentre elas a Matemática (BRASIL, 2006). Essa docência, via de regra, não deve se confundir com a utilização de métodos e técnicas pedagógicas que não estejam conectadas às realidades históricas específicas, mas constitui-se "na confluência de conhecimentos oriundos de diferentes tradições culturais e das ciências, bem como de valores, posturas e atitudes éticas, de manifestações estéticas, lúdicas, laborais" (BRASIL, 2005, p. 7).

No âmbito da Educação, recentes pesquisas têm se dedicado a compreender aspectos atrelados aos conhecimentos específicos de diferentes áreas de conhecimento, como é o caso de Gatti e Nunes (2009), que analisaram as propostas disciplinares e os conteúdos formadores dos cursos presenciais de licenciatura em Pedagogia, Língua Portuguesa, Matemática e Ciências Biológicas das universidades brasileiras.

Além disso, a formação matemática de pedagogos também tem sido uma questão recorrente na pesquisa educacional. Por exemplo, Curi (2005, 2013) discute o espaço destinado à formação matemática nos cursos de Pedagogia e apresenta atividades de desenvolvimento profissional nas quais vem trabalhando em sua prática como formadora.

Da mesma forma, Borba e Curi (2016) apresentam diversos trabalhos de pesquisadores brasileiros que desenvolveram pesquisas relacionadas à Matemática na 
Educação Infantil e nos Anos Iniciais do Ensino Fundamental. Destacam, por exemplo, trabalhos que lidaram com a compreensão dos conhecimentos de alunos e professores sobre conteúdos matemáticos, com propostas curriculares e com recursos didáticos para o ensino de Matemática na formação de pedagogos.

No âmbito da pesquisa voltada à formação de professores, um caminho recorrentemente trilhado tem sido o uso de narrativas. Em Nacarato, Mengali e Passos (2009), é possível encontrar uma discussão sobre as potencialidades do uso de narrativas em sala de aula, nos diferentes níveis de ensino, em diferentes contextos de formação de professores (na formação inicial ou em programas de formação continuada e/ou grupos de trabalhos colaborativos) e, ainda, em pesquisas no âmbito educacional. Silva e Garnica (2015), Silva, Alves e Miranda (2013), Nacarato e Passeggi (2013) e Carneiro (2014) também são exemplos de pesquisas que utilizaram narrativas para discutir a formação inicial de pedagogos.

Consideramos que a formação matemática de pedagogos não se inicia somente por meio do curso de Pedagogia, como temos visto em nossas experiências de formadores de professores e em trabalhos como Curi (2005), Nacarato (2010), e Nacarato, Mengali e Passos (2009). Ela se inicia antes do ingresso do estudante no curso de Pedagogia, por meio de suas vivências escolares, nas quais o modo como seus professores atuaram e abordaram a Matemática pode gerar exemplos para suas práticas futuras. Da mesma forma, vivências não escolares também modelam a formação do futuro pedagogo antes do acesso à universidade, permeadas por atividades desenvolvidas com a família ou, em um aspecto geral, fora da escola.

Dessa forma, se a formação matemática ocorre desde as vivências fora da escola, assim como na Educação Básica, é possível questionar como ela tem influenciado os futuros pedagogos quando se deparam com as disciplinas relacionadas à Matemática no curso de Pedagogia. Nesse sentido, um dos objetivos deste artigo é analisar narrativas escritas e orais produzidas por estudantes do curso de Pedagogia de uma Universidade Federal, localizada no sul de Minas Gerais, visando compreender a forma como as experiências com a Matemática, anteriores ao ingresso na universidade, podem influenciar suas concepções e atitudes frente a esta disciplina.

Para tanto, foram analisadas 23 narrativas escritas e orais de estudantes ${ }^{1}$ do curso de Pedagogia da Universidade Federal de Alfenas (UNIFAL-MG), aplicadas no início da disciplina "Matemática: Fundamentos e Metodologias I", frequentadas por alunos

\footnotetext{
${ }^{1}$ As turmas eram compostas majoritariamente por estudantes do gênero feminino.
} 
predominantemente do sétimo período do curso. Essa análise foi realizada com base em nossa leitura dessas narrativas, isto é, por meio de nossa produção de significados para elas (LINS, 2012), tendo em vista o que foi levantado pelos estudantes.

Além disso, respaldados em Curi (2005) e Gatti e Nunes (2009), buscamos neste trabalho discutir como a Matemática tem sido abordada nos currículos dos cursos de Pedagogia, com foco especial na instituição em que trabalhamos, visando apontar pontos que podem contribuir para a prática de formação matemática de pedagogos, uma vez que o encontro de experiências com a Matemática anterior ao ingresso no curso de Pedagogia com a oferta de experiências matemáticas por esse curso se dá, praticamente, nas disciplinas de Matemática.

Este artigo se estrutura na forma de quadros. No primeiro trazemos os estudos de Curi (2005) e Gatti e Nunes (2009) sobre a formação matemática nos currículos dos cursos de Pedagogia, evidenciando o pouco espaço destinado à Educação Matemática de futuros pedagogos. No segundo quadro, apresentamos nossas leituras das narrativas de futuros pedagogos e pedagogas, juntamente com discussões teóricas sobre elas. Por fim, apresentamos, na última seção, um possível encontro destes dois quadros, no qual levantamos algumas considerações sobre a formação de futuros pedagogos do ponto de vista do formador.

\section{Primeiro quadro: a formação matemática nos cursos de Pedagogia}

Curi (2005) apresenta a trajetória histórica da formação matemática de professores dos Anos Iniciais do Ensino Fundamental, buscando indícios da forma como eram tratadas as três vertentes do conhecimento: os conhecimentos de conteúdos matemáticos, os conhecimentos didáticos desses conteúdos e os conhecimentos relativos aos currículos de Matemática ${ }^{2}$.

Para exibir um quadro atual da formação matemática desses professores, Curi (2005) fez uma análise das ementas das disciplinas da área de Matemática de 36 cursos de Pedagogia. Estes cursos foram selecionados através das ementas que foram disponibilizadas na Internet e por terem sido reformulados a partir do ano 2000. A autora constatou que a disciplina do tipo "Metodologia de Ensino e Matemática" foi a que mais apareceu nas grades curriculares, em mais de dois terços dos cursos analisados.

Além disso, verificou que outros $25 \%$ dos cursos possuíam a disciplina "Conteúdos e Metodologias de Ensino de Matemática” em suas grades. Ou seja, Curi (2005) constatou que

\footnotetext{
${ }^{2}$ Esses tipos de conhecimentos foram apresentados por Shulman (1992 apud CURI, 2005).
} 
cerca de $90 \%$ dos cursos de Pedagogia elegem as questões metodológicas como essenciais no que tange à formação de professores polivalentes.

Como a denominação das disciplinas não garante que haja uma homogeneidade na forma de abordar os conteúdos, a análise das ementas dos cursos selecionados foi feita com base nas três vertentes do conhecimento listadas anteriormente. A partir disso, Curi (2005) verificou que a carga horária destinada às disciplinas da área de Educação Matemática mostrou-se reduzida e que os conteúdos matemáticos mais abordados foram a construção do número e as quatro operações envolvendo números naturais e racionais.

Uma das conclusões de Curi (2005) foi de que o conhecimento "de e sobre" Matemática mostrou-se pouco enfatizado, mesmo em relação aqueles conteúdos que deveriam ser trabalhados com os estudantes dos Anos Iniciais do Ensino Fundamental, principalmente em relação aos blocos de conteúdos trazidos pelos Parâmetros Curriculares Nacionais (PCNs) (BRASIL, 1997), como Grandezas e Medidas, Espaço e Forma e Tratamento da Informação. Como consequência, os pedagogos que frequentaram estes cursos possivelmente concluíram sua formação inicial sem um contato adequado com os conteúdos que irão ensinar, tanto no que diz respeito aos conceitos e procedimentos quanto à própria linguagem matemática. Nas palavras de Curi (2005, p. 70), "parece haver uma concepção dominante de que o professor polivalente não precisa 'saber matemática' e que basta saber como ensiná-la”.

Já em Gatti e Nunes (2009), é possível encontrar ampla discussão em relação aos currículos dos cursos de Pedagogia, em nível nacional. As autoras organizaram um estudo que objetivou analisar o que tem sido proposto pelas Instituições de Ensino Superior (IES) como disciplinas e conteúdos formadores dos cursos presenciais das licenciaturas (Língua Portuguesa, Pedagogia, Matemática e Ciências Biológicas). Além disso, buscaram verificar quais eram as expectativas dos editais de concursos públicos para contratação de professores na rede pública de ensino para atuarem no Ensino Fundamental.

Em relação às licenciaturas em Pedagogia, Gatti e Nunes (2009) iniciaram suas análises fazendo um mapeamento das IES, por categoria administrativa (pública, privada, filantrópica/confessional/comunitária) e por organização acadêmica (universidade ou centro universitário, ou faculdade integrada, isolada/escolas/instituto superior de educação), fornecendo o número de cursos e alunos matriculados nos cursos de Pedagogia em 2001, 2004 e 2006, e dados do ENADE (Exame Nacional de Desempenho dos Estudantes).

A partir disso, as autoras constituíram uma amostra de 71 cursos de Pedagogia presenciais para um estudo mais detalhado de seus currículos, baseadas em uma distribuição 
proporcional do mapeamento realizado, levando em consideração a localização dos cursos nas cinco regiões do Brasil, a categoria administrativa e a organização acadêmica das IES.

Para a análise dos cursos de Pedagogia, Gatti e Nunes (2009) se basearam, inicialmente, em Brasil (2005, 2006) e criaram as seguintes categorias de análise: Fundamentos Teóricos da Educação; Conhecimentos Relativos aos Sistemas Educacionais; Conhecimentos Relativos à Formação Profissional Específica; Conhecimentos Relativos a Modalidades e Nível de Ensino Específicos; Outros Saberes; Pesquisa e Trabalho de Conclusão de Curso (TCC); e Atividades Complementares.

De especial interesse para este artigo, queremos destacar duas categorias. Na categoria denominada "Fundamentos Teóricos da Educação", estavam presentes as disciplinas que tinham o papel de embasar teoricamente o estudante de Pedagogia a partir de áreas do conhecimento como Antropologia, Estatística, História, Psicologia, Sociologia, entre outras, com as áreas correlatas no campo da Educação.

A segunda categoria, denominada de "Conhecimentos Relativos à Formação Profissional Específica", foi composta pelas disciplinas do curso que são responsáveis por fornecer o instrumental para a ação do professor, dentre as quais, por exemplo, as disciplinas relacionadas à Matemática.

Os resultados do estudo de Gatti e Nunes (2009) mostraram que as disciplinas, com suas respectivas cargas horárias, foram distribuídas em uma mesma proporção em ambas as categorias. Além disso, elas trouxeram indícios de que a relação teoria-prática, tão preconizada pelos documentos oficiais ${ }^{3}$ e pelas discussões na área da Educação, mostra-se comprometida.

Nesse sentindo, Gatti e Nunes (2009) avaliaram que as disciplinas que compõem a categoria "Conhecimentos Relativos à Formação Profissional Específica" também possuem conteúdos que expressam uma predominância de aspectos teóricos que fundamentam as teorias de ensino presentes nas variadas áreas do conhecimento, como das Ciências da Natureza, Sociologia, Psicologia, entre outras.

Contudo, pouco contemplam possibilidades de práticas educacionais que estejam associadas a estes aspectos. Gatti e Nunes (2009) ressaltaram que as disciplinas contidas neste grupo possuem ementas que refletem uma preocupação mais acentuada com as justificativas sobre o "porquê ensinar", fato que, de certa forma, seria importante para evitar que tais

\footnotetext{
${ }^{3}$ Veja, por exemplo, Brasil (2005, 2006).
} 
disciplinas se transformassem em simples receituários. Porém, segundo as autoras, tais disciplinas registram o "o quê" e o "como" ensinar de uma maneira muito introdutória.

Ainda de acordo com Gatti e Nunes (2009, p. 22), existem "instituições que propõem o estudo dos conteúdos de ensino associados às metodologias, mas, mesmo assim, de forma panorâmica e pouco aprofundada". Elas concluem que, mesmo no conjunto das disciplinas classificadas como voltadas à formação profissional mais específica, as ementas sugerem que o estudo dos conteúdos também é feito de forma muito insuficiente.

As autoras evidenciam resultados que se aproximam das discussões feitas por Curi (2005), quais sejam, de que os conteúdos das disciplinas específicas são feitos de forma insuficiente ao que consideram que deveriam ser, e não são objetos dos cursos de formação inicial de pedagogos. Mesmo quando os conteúdos específicos são associados às metodologias de ensino, ainda assim eles são trabalhados de forma panorâmica e pouco aprofundada. Nas palavras de Gatti e Nunes:

Em síntese, no que se refere às metodologias de ensino, há ementas que revelam esforço de abarcar estudos dos conteúdos específicos e estudo dos métodos para ensinar, considerando que este é o único espaço em que comparece o que foi identificado como conteúdos específicos na quase totalidade das ementas analisadas (GATTI; NUNES, 2009, p. 39).

É interessante notar que Gatti e Nunes (2009) apontaram para uma carência de formação dos conteúdos específicos, no aspecto do "o quê" e do "como" ensinar para a prática docente em sala de aula e para a importância da contextualização na perspectiva da história do tempo e espaço da produção de determinado conceito e de sua trajetória como campo disciplinar. Elas também apontaram para a insuficiência de possíveis problematizações para os significados construídos pelos alunos, ou, dito de outro modo, a necessidade de um aprofundamento suficiente para que os professores proponham desafios capazes de favorecer o estabelecimento de relações entre os saberes escolares e a experiência cotidiana dos discentes (GATTI; NUNES, 2009). Tal carência apontada por Gatti e Nunes (2009) é justamente o que é preconizado em Brasil (2005).

Esse quadro geral, relacionado ao pequeno espaço destinado à formação matemática de pedagogos, também é refletido em nossa prática profissional, como docentes do curso de Pedagogia da Universidade Federal de Alfenas (UNIFAL-MG). As disciplinas da área de Educação Matemática, denominadas nesta instituição de "Matemática: Metodologias e Fundamentos I" e "Matemática: Metodologias e Fundamentos II", estão inseridas no eixo "Docência na Educação Infantil e nos Anos Iniciais do Ensino Fundamental", dentro do chamado "Núcleo de Estudos Básicos", constituído por disciplinas que visam propiciar 
embasamento teórico das principais correntes do pensamento pedagógico e disciplinas que objetivam preparar o futuro pedagogo para atuar como docente na Educação Infantil e nos Anos Iniciais do Ensino Fundamental ${ }^{4}$. A carga horária total do curso é de 3.100 horas e a carga horária destinada às duas disciplinas da área de Educação Matemática é de 90 horas teóricas, sendo 60 horas para a primeira e 30 horas para a segunda, além de 15 horas de prática pedagógica em cada uma delas (UNIVERSIDADE FEDERAL DE ALFENAS, 2011).

Na primeira disciplina, o foco está no tema "Números e Operações", tanto no aspecto conceitual, quanto no modo de trabalhar tal tema na Educação Básica. Na segunda disciplina, o foco está no tema "Grandezas e Medidas", no qual também se explora o aspecto conceitual deste tema e o modo de lidar com ele na Educação Básica. Se formos pensar em termos dos PCN (BRASIL, 1997), estes temas referem-se aos blocos de conteúdos "Números e Operações" e "Grandezas e Medidas". Como sabemos da importância dos outros dois blocos ("Espaço e Forma" e "Tratamento da Informação"), temos tentado abordá-los nas duas disciplinas mencionadas, mesmo porque o curso de Pedagogia, no nosso ponto de vista, oferece uma ótima oportunidade de trabalhar de forma interdisciplinar, até mesmo dentro da própria Matemática.

\section{Segundo quadro: a formação matemática dos futuros pedagogos antes de ingressarem no curso de Pedagogia}

Como mencionamos, para analisar a formação matemática de futuros pedagogos na época em que cursavam a Educação Básica, temos trabalhado na linha das narrativas escritas e orais com as turmas do curso de Pedagogia em que atuamos. No sentido de que:

\footnotetext{
Narrar é contar uma história, narrar-se é contar nossa história ou uma história da qual também somos, fomos ou nos sentimos personagens. Esse contar, é importante ressaltar, se dá sempre em direção a alguém. Desse modo, a narração prevê um posicionamento frente ao outro (CURY; SOUZA; SILVA, 2014, p. 915).
}

Enquanto professores da área de Educação Matemática do curso de Pedagogia na disciplina "Matemática: Fundamentos e Metodologias I", temos solicitado que os alunos narrem, de forma escrita, sobre a Matemática nas suas vidas, com um recorte especial para a

\footnotetext{
${ }^{4}$ No Projeto Pedagógico do Curso de Pedagogia da UNIFAL-MG, são propostos três núcleos: o "Núcleo de Estudos Básicos", já citado anteriormente; o "Núcleo de Aprofundamento e Diversificação de Estudos", que visa preparar o futuro pedagogo para participar da organização e gestão de sistemas e instituições de ensino, do desenvolvimento de pesquisa e para o atendimento de diferentes demandas sociais; e, por fim, o "Núcleo de Estudos Integradores", composto por atividades formativas e estágios, que são atividades que objetivam proporcionar um enriquecimento curricular mediante a participação em atividades teóricas e práticas que não se limitam às disciplinas do curso (UNIVERSIDADE FEDERAL DE ALFENAS, 2011).
} 
vida escolar. Este é um primeiro momento, no qual cada um volta o olhar para si, para sua experiência vivenciada, trazendo aquilo que lembra sobre o processo escolar e pensando em como a Matemática está presente em seu dia a dia. Como diz Bondía (2014):

\begin{abstract}
A experiência é o que nos passa, o relato é um dos modos privilegiados de como tratamos de dar sentido narrativo a isso que nos passa e o sujeito da experiência, convertido no sujeito do relato, é o autor, o narrador é o personagem principal dessa trama de sentido e de sem-sentido que construímos como nossa vida e que, ao mesmo tempo, nos constrói (BONDÍA, 2014, p. 722, grifos do autor).
\end{abstract}

Após essa escrita, propiciamos um momento em que cada aluno pode contar sua narrativa. As formas de contar as narrativas, observadas por nós até agora, foram: leitura do que escreveram, relato do que escreveram recorrendo à narrativa, mas acrescentando mais detalhes, e relato de suas experiências sem recorrer à narrativa. Neste momento coletivo, cada um conhece as experiências dos outros estudantes, reconhece-se (ou não) nas narrativas compartilhadas, lembra-se de outros eventos que aconteceram em suas vidas, e sobre os quais não escreveu, compartilha suas visões de educação e sentimentos que foram despertados. $\mathrm{O}$ registro desse momento é feito por meio de anotações dos pesquisadores.

Consideramos esse processo importante porque, concordando com Nacarato, Mengali e Passos (2009), as narrativas possibilitam a reorganização das experiências, revelam as crenças com relação à Matemática e seu ensino e aprendizagem, possibilitam a identificação de tendências didático-pedagógicas e também trazem marcas de um período histórico da Educação Matemática.

Esse é um uso importante das palavras na formação de professores da Educação Infantil e dos Anos Iniciais do Ensino Fundamental, pois, como diz Bondía (2002), fazemos coisas com as palavras e elas fazem coisas com a gente, elas dão sentido ao que somos e ao que nos acontece e, também, "tem a ver com as palavras o modo como nos colocamos diante de nós mesmos, diante dos outros e diante do mundo em que vivemos. E o modo como agimos em relação a tudo isso" (BONDÍA, 2002, p. 21).

Assim como as narrativas possibilitam um olhar para nós mesmos e para os outros, por meio das discussões propiciadas por elas na sala de aula, consideramos que as mesmas podem ser analisadas por um processo de produção de significados, que pode ser entendido como tudo o que se pode e efetivamente se diz de algo em uma situação ou atividade (LINS, 1999, 2012). Esse processo se inicia a partir do momento em que nós, professores, solicitamos as narrativas para nossos alunos, com o intuito de conhecê-los, pois compartilhamos da seguinte postura educacional:

Não sei como você é; preciso saber. Não sei também onde você está (sei apenas que está em algum lugar); preciso saber onde você está para que eu possa ir até lá falar 
com você e para que possamos nos entender, e negociar um projeto no qual eu gostaria que estivesse presente a perspectiva de você ir a lugares novos (LINS, 1999, p. 85).

No processo de analisar as narrativas, para conhecer melhor nossos alunos, é importante mencionar que o que foi narrado e o que foi vivido pode apresentar certas diferenças. Narrar já é uma leitura, uma produção de significado, do que foi vivido, pois é um olhar atual para o que ocorreu no passado. Ao narrar, o narrador dirige suas palavras escritas e orais para um interlocutor que é constituído em determinado momento e com determinados objetivos, sendo que o interlocutor "é uma direção na qual se fala. Quando falo na direção de um interlocutor é porque acredito que este interlocutor diria o que estou dizendo e aceitaria/adotaria a justificação que me autoriza a dizer o que estou dizendo" (LINS, 2012, p. 19). Pode ser que os estudantes dissessem coisas diferentes sobre Matemática ao falar com outras pessoas em outros contextos de atividade. Mas, como não temos acesso a esse pode ser dito, nossa análise é feita sobre o que foi dito e sobre o que consideramos marcante em termos de formação de professores contido nas narrativas.

Em relação à análise das narrativas, ou seja, da nossa produção de significados para elas, concentramo-nos em analisar, por meio de categorizações, as que recentemente solicitamos aos estudantes, ou seja, as 23 narrativas escritas e orais trabalhadas com alunos que estavam cursando a disciplina "Matemática: Fundamentos e Metodologias I". Já entrando no aspecto da análise, vimos que o processo de narrar de forma escrita e oral traz marcas profundas de um passado escolar com a Matemática, que, na maioria das narrativas, se apresentaram inicialmente pela frase: "sempre tive dificuldades com a matemática", ou "minha experiência com a matemática não foi prazerosa", ou então "as minhas experiências com a matemática até hoje não foram as melhores". Nós categorizamos frases deste tipo como visão geral da relação com a Matemática. A partir dessa visão geral, algumas narrativas trazem aspectos mais específicos sobre essas dificuldades, como pode ser visto pelo trecho abaixo:

Sempre tive muita dificuldade com as operações matemáticas, mesmo com as contas simples de divisão, por exemplo, encontro dificuldades. Números, operações, frações sempre foram conteúdos abstratos para mim.

(Trecho da Narrativa 1, 2017).

O trecho mencionado traz, como aspecto específico das dificuldades enfrentadas, os próprios conteúdos matemáticos. Mas essa dificuldade não está relacionada somente à Matemática. Ela está relacionada, também, aquilo que categorizamos como postura dos 
professores. Eles parecem ter o poder de fazer os estudantes gostarem mais ou menos de Matemática, como podemos ver nos seguintes trechos:

Minha experiência com a disciplina de matemática infelizmente não foi muito agradável, as professoras de ensino fundamental e médio nunca tiveram uma didática inclusiva, os alunos não acompanhavam o raciocínio com a professora.

(Trecho da Narrativa 5, 2017).

Durante a vida escolar tive experiências ótimas, com professores excelentes, até um belo semestre aparecer uma professora substituta que não era tão boa quanto a titular e brigamos. Até então, eu amava a matemática. Depois disso, tinha raiva de ir para a escola, principalmente para a aula de matemática.

(Trecho da Narrativa 2, 2017).

Quando criança, nos anos iniciais, a matemática que aprendia era muito lúdica e a professora propunha para nós brincadeiras que envolviam cálculos matemáticos. Era prazeroso aprender com ela, tanto que quando ela pedia para abrirmos o caderno de matemática, sabíamos que a diversão era garantida. [...]. Porém, crescemos um pouco e ao iniciar a $5^{a}$ série tive como professor um sujeito sem comentários, então perdi o interesse e minha relação com a matemática da sala de aula nunca mais foi a mesma, eu sentia que era complicado aprender matemática.

(Trecho da Narrativa 3, 2017).

Uma fala trazida no momento coletivo, relacionada à postura do professor, foi: "tive aula com um professor que não acreditava no que ele próprio fazia, ele sentava na cadeira, pedia para abrirmos o livro e resolvermos os exercícios dele, e ficava mexendo no laptop; se ele não acreditava, como eu poderia acreditar ou gostar?" (Anotações dos docentes, 2017).

Os trechos das narrativas citados evidenciam a influência do professor no gostar ou não da Matemática. Segundo Nacarato (2010), quando o professor é colocado no centro da atividade educacional, sendo aquele que transmite o conteúdo e o aluno aquele que recebe esse conteúdo, o aluno estabelece muito mais uma relação com o professor do que com o conteúdo e, dessa forma, a figura do professor fica mais marcante nas lembranças que são trazidas para as narrativas.

Em apenas uma das narrativas analisadas, em anos que fazemos essa atividade, a responsabilização pela dificuldade de aprendizagem dos conteúdos matemáticos foi colocada na própria aluna, como pode ser visto no recorte da narrativa:

Por fim, minha experiência não foi tão negativa, eu só tinha dificuldade para aprender, a culpa não era da professora e nem da sala, a dificuldade era minha mesmo.

(Trecho da Narrativa 7, 2017).

Isso mostra o quanto os alunos não se colocam e nem são colocados como sujeitos da aprendizagem, o que talvez faça com que eles não se sintam responsáveis pela sua produção de conhecimentos. 
Mesmo relatando dificuldades com a Matemática, as narrativas trouxeram um aspecto de uso da matemática na vida, categoria construída por nós, na qual esse uso não é problemático. Muitos dos estudantes utilizam a Matemática em suas atividades laborais ou cotidianas, seja para fazer cálculo de banco de horas, transações comerciais, entre outras, como pode ser visto no trecho abaixo:

Agora tenho uma relação agradável com a matemática [...]. Trabalho com artesanato, tenho que diariamente medir peças, traçar, recortar exatamente peças do mesmo tamanho e formas $e$ isso sem contar que tenho que fazer contas de gastos, lucros. Realizar compras e fazer orçamentos, sempre trabalhando com números. Acho que é essa minha relação com a matemática e ela é importantíssima na minha vida.

(Trecho da Narrativa 4, 2017).

É interessante notar que, no solo das vivências fora da escola, a Matemática não se apresenta como um problema, mas na escola sim. Há um distanciamento entre as atividades realizadas na escola e fora dela. Para Lins (1999), a escola, tradicionalmente, negou os significados da rua, isto é, os significados fora da escola ou não escolares, e se esforçou para implementar os significados escolares, no caso da Matemática, os significados matemáticos oficiais.

Nesse caso, não se trata de a escola negar os significados da rua ou de a rua negar os significados da escola, mas de tentar trabalhar, tanto na escola quanto nos cursos de formação de professores, na linha de ampliação dos significados que são legítimos em diferentes práticas sociais. Isso não foi visto nas narrativas, assim como foram trazidas poucas lembranças de diversidade de recursos didáticos relacionadas à categoria modos de lidar com os conteúdos em salas de aula, mostrando-nos um ensino pautado na exposição de conteúdos primeiro e, depois, na resolução de exercícios, em outras palavras, pautado no paradigma do exercício (SKOVSMOSE, 2014).

Quando uma narrativa fala sobre uma abordagem diferente da mencionada, ou seja, a utilização de algum recurso didático pelo professor, coloca vários exemplos, como: cálculos mentais, problemas para resolver adição, brincadeiras, bingo, material dourado, palitos de picolé, tampinha de garrafa e música. Tais modos de lidar com os conteúdos trazem a diferença entre o que os documentos oficiais propõem para o ensino de Matemática, como é o caso dos PCN (BRASIL, 1997), e o que acontece efetivamente nas práticas escolares, cabendo a professores isolados a escolha pelo modo como abordarão a Matemática.

O conteúdo matemático mais citado nas narrativas foi a tabuada, atrelado a um modo "decoreba" de lidar com ela. Na maioria das narrativas, o "decorar a tabuada" aparece como 
uma performance exigida pelo professor e, caso isso não ocorresse, poderia haver consequências não tão positivas, como vemos no trecho da narrativa a seguir:

Na minha vida escolar me lembro de quando foi me ensinado a tabuada. A professora combinou que todos os dias ela iria para o fundo da sala tomar tabuada individualmente $e$, conforme os alunos iam decorando, iam sendo liberados desta atividade. Com a minha dificuldade, fui a última da turma a ser liberada.

(Trecho da Narrativa 1, 2017).

Além de ter consequências por não decorar a tabuada, esta era utilizada de forma punitiva pelos professores, em momentos em que os alunos faziam algo visto como negativo pelo professor, não necessariamente em aulas de Matemática.

A professora, por todas as vezes, ensinava o conteúdo de maneira maçante, e, dizia que precisávamos decorar a tabuada. Quando algum aluno desobedecia às regras, a professora deixava-o de castigo durante o recreio repetindo a tabuada dez vezes numa folha de sulfite. Recordo-me perfeitamente que um dia eu fiquei de castigo, pois não colori um desenho, $e$ repeti a tabuada do 5 por dez vezes, no sol. Depois disso, nunca mais esqueci nem a tabuada do 5 , nem a rigidez da professora.

(Trecho da Narrativa 6, 2017).

As atitudes experienciadas pelos futuros pedagogos em relação à tabuada e à postura dos professores de forma punitiva, ou então que se traduzem em falas como "as aulas de matemática sempre foram com cobranças e opressão" (trecho da Narrativa 5, 2017), podem ser consideradas como exemplos de microagressões relacionadas aos conteúdos matemáticos (SILVA; POWELL, 2016).

O conceito de microagressões está atrelado às formas mais ou menos sutis e nebulosas de insultos verbais e não verbais proferidos contra indivíduos por questões fortemente relacionadas a raça, gênero, etnia, religião e idioma (SOLÓRZANO; CEJA; YOSSO, 2000; SOLÓRZANO; YOSSO, 2002; SUE et al., 2007). Contudo, Silva e Powell (2016) discutem a forma como microagressões também podem ser relacionadas a atitudes direcionadas aos conteúdos escolares, como os da Matemática, por exemplo, e enfatizam que podem influenciar negativamente a trajetória acadêmica dos estudantes, deixando-os com a sensação de que realmente não deveriam estar naquele local ou de que a Matemática é algo que realmente não é para eles.

Na palavra microagressão, o prefixo micro geralmente causa uma falsa impressão de que o insulto pode ser considerado algo pequeno ou mesmo sem maiores consequências. $\mathrm{Na}$ verdade, microagressão significa "que a agressão incide em um nível individual e/ou local, ou mesmo em situações 'privadas' ou limitadas, que permitem certo grau de anonimato por parte do agressor" (SILVA; POWELL, 2016, p. 45). 
Como é possível notar nas narrativas das estudantes mencionadas anteriormente, as microagressões experienciadas por elas, em seus percursos na Educação Básica, contribuíram para a formulação de concepções negativas quanto à Matemática, fato que ainda causava muito desconforto quando elas falavam sobre isso e que pode refletir em sua formação profissional. Dessa forma, as narrativas propiciaram que esses pontos viessem à tona e que outros estudantes compartilhassem experiências semelhantes.

Outro ponto que surgiu a partir das narrativas que analisamos diz respeito ao que denominamos de ênfase na alfabetização. Essa categoria traz narrativas que evidenciam como o pouco espaço na formação inicial de professores dos Anos Iniciais pode favorecer a continuação de um ciclo, priorizando certos assuntos em relação a outros. O trecho a seguir destaca um sentimento comum entre as futuras pedagogas que participaram do estudo:

Sempre tive um pré-conceito com a matemática. Este pré-conceito nasceu pela falta de oportunidade de estudar e trabalhar a disciplina com professores que tivesse o interesse de ensinar a matemática e não somente a alfabetização.

(Trecho da Narrativa 5, 2017).

A ênfase na alfabetização é vista pelos estudantes como algo feito na Língua Portuguesa, deixando de lado conhecimentos específicos, como a Matemática. Por mais que o Plano Nacional pela Alfabetização na Idade Certa (PNAIC), no qual os governos se comprometeram a alfabetizar todas as crianças até os oito anos de idade ${ }^{5}$, tenha contemplado a Matemática, as narrativas orais apontam para uma convergência em se ver a alfabetização como algo atrelado à Língua Portuguesa, reforçada pelas observações das práticas dos professores em serviço, realizadas durante os estágios obrigatórios e projetos de iniciação à pesquisa e de extensão desenvolvidos no âmbito da escola. Consideramos que este ponto se apresenta como uma possibilidade de futuras investigações no campo da Educação em nível geral, e na Educação Matemática em particular.

Por meio das narrativas, foi possível analisar como foi a relação de nossos alunos e alunas com a Matemática, antes de ingressarem no curso de Pedagogia, e como se relacionam com a Matemática atualmente. Um último aspecto que queremos trazer de nossas análises é que, por mais que não tivéssemos solicitado, muitos estudantes trouxeram o desejo de aprender Matemática ou diminuir as dificuldades que possuíam para poderem atuar em salas de aula de forma diferente dos professores que tiveram. Esse sentimento pode ser capturado no seguinte trecho de uma das narrativas:

\footnotetext{
${ }^{5}$ Mais informações sobre o Plano Nacional pela Alfabetização na Idade Certa podem ser acessadas em: <http://pacto.mec.gov.br/o-pacto>. Acesso em: 30 jun. 2017.
} 
[...] nessa disciplina eu pretendo amenizar todos os meus bloqueios e dificuldades, de modo que depois de formar eu consiga passar boas experiências e ensinamentos para meus futuros alunos.

(Trecho da Narrativa 6, 2017).

Nesse sentido, os futuros pedagogos e pedagogas valorizam sua formação inicial e veem as disciplinas de "Matemática: Fundamentos e Metodologias I e II" como uma forma de enfrentamento das dificuldades acadêmicas decorrentes da Educação Básica.

\section{Quando os quadros se encontram: considerações sobre a formação de futuros pedagogos}

No primeiro quadro, destacamos, por meio da literatura, que a formação matemática de futuros pedagogos tem pouco espaço nas dinâmicas curriculares de cursos de Pedagogia, como é o caso da universidade onde atuamos, na qual as disciplinas da área de Educação Matemática correspondem em torno de $4 \%$ da carga horária total do curso. Além disso, os conteúdos matemáticos ocupam uma posição de igualdade ou inferioridade em relação às questões metodológicas, concentrando-se, principalmente, no tema "Números e Operações". Isso pode ser prejudicial em termos de práticas futuras, uma vez que trabalhar com temas que não conhece ou se sente confiante pode fazer com que o professor evite lidar com eles. Um exemplo disso é o abandono da geometria por parte de muitos professores, como abordado por Caldatto e Pavanello (2015), sendo a não formação geométrica dos professores um motivo para este abandono.

No segundo quadro, fizemos uma leitura das narrativas, escritas e orais, produzidas por nossos alunos e alunas, visando conhecê-los melhor em relação aos seus processos de formação matemática e sobre suas visões de mundo sobre a Matemática.

As narrativas fomentam uma contínua compreensão dos processos de formação e ensino de/em Matemática e nos possibilitaram ler uma formação matemática que ocorreu na Educação Básica e que deixou marcas profundas, como foi o caso das microagressões relacionadas ao conteúdo matemático, por exemplo. Evidenciou-se um passado marcado, em relação à Matemática, na maioria das vezes, por experiências ruins e dificuldades, ao mesmo tempo em que a Matemática vivenciada fora da escola foi narrada como importante nas atividades cotidianas. Esse fato pode abrir novos caminhos para futuras pesquisas que 
aprofundem a discussão sobre qual Matemática é essa que os narradores usam e consideram importante em suas práticas ${ }^{6}$.

O encontro dos dois quadros acontece na disciplina da área de Educação Matemática para o curso de Pedagogia e, de certa forma, ocorre quando o formador (ou seja, o educador que lidará com a reduzida carga horária destinada à Educação Matemática) entra em contato com as experiências narradas pelos futuros pedagogos.

Cada formador possui suas próprias experiências de formação e também relacionadas à Matemática. Possui igualmente uma crença em relação à Matemática e à Educação Matemática que pratica, fato que influencia no modo de lidar com os futuros pedagogos e com as disciplinas da área de Educação Matemática do curso. Dessa forma, mediante as experiências narradas pelos estudantes, queremos concluir este artigo apresentando dois pontos importantes de serem levados em consideração na prática de formação matemática de pedagogos.

O primeiro está relacionado com as marcas profundas na vivência escolar, como as microagressões trazidas pelos futuros pedagogos e pelas futuras pedagogas, o que requer um cuidado contínuo para não produzir ou reproduzir situações semelhantes às vividas no passado por eles e que aumentem a relação de dificuldade com a Matemática.

Por fim, o segundo se refere aos conteúdos e metodologias, tão enfatizados pelas pesquisas de Curi (2005) e Gatti e Nunes (2009). A análise das narrativas foi embasada em Lins $(1999,2012)$. Este autor considera que o aspecto central de toda aprendizagem é a produção de significados, o que implica em produção de conhecimentos. Ainda que exista uma baixa carga horária para as disciplinas de Matemática, os conteúdos matemáticos e as metodologias podem ser abordados de forma que os futuros pedagogos produzam significados para eles com o objetivo de ampliação do repertório matemático, maior confiança na prática docente e aprimoramento de leituras dos alunos e do que acontece em salas de aula. Essa abordagem pode colocar os futuros pedagogos e pedagogas, diferentemente das experiências narradas, como protagonistas de um processo de formação matemática que é, de acordo com Nacarato, Mengali e Passos (2009), pessoal, múltiplo, histórico, mutável e inconcluso.

\section{Referências bibliográficas}

BONDÍA, J. L. Notas sobre a experiência e o saber de experiência. Revista Brasileira de Educação, Rio de Janeiro, n. 19, p. 20-28, 2002.

\footnotetext{
${ }^{6}$ A relação da Matemática na escola e fora dela, e que Matemática é essa que é vivenciada na rua, se apresentam como um campo interessante de investigação. Veja, por exemplo, Knijnik (2017).
} 
BONDÍA, J. L. 20 minutos na fila: sobre experiência, relato e subjetividade em Imre Kertész. Boletim de Educação Matemática, Rio Claro, v. 28, n. 49, p. 717-743, 2014.

BORBA, R.; CURI, E. Educação Matemática na Educação Infantil e nos Anos Iniciais do Ensino Fundamental. Perspectivas da Educação Matemática, Campo Grande, v. 9, n. 21, p. 594-599, 2016.

BRASIL. Secretaria de Educação Fundamental. Parâmetros Curriculares Nacionais: matemática (1 ${ }^{\mathrm{a}}$ a $4^{a}$ séries). Brasília: MEC/SEF, 1997.

BRASIL. Conselho Nacional de Educação. Diretrizes Curriculares Nacionais para o Curso de Pedagogia. Parecer CNE/CP n. 5 de 13 de dezembro de 2005. Brasília, 2005. Disponível em: <http://portal.mec.gov.br/cne/arquivos/pdf/pcp05_05.pdf>. Acesso em: 2 fev. 2017.

BRASIL. Conselho Nacional de Educação. Diretrizes Curriculares Nacionais para o Curso de Graduação em Pedagogia, licenciatura. Resolução CNE/CP n. 1 de 15 de maio de 2006. Brasília: Ministério da Educação, 2006. Disponível em: <http://portal.mec.gov.br/cne/arquivos/pdf/rcp01_06.pdf>. Acesso em: 10 mar. 2017.

CALDATTO, M. E.; PAVANELLO, R. M. Um panorama histórico do ensino de geometria no Brasil: de 1500 até os dias atuais. Quadrante, Lisboa, Portugal, v. XXIV, n. 1, p. 103-128, 2015.

CARNEIRO, R. F. Narrativas de alunas-professoras dos anos iniciais do ensino fundamental: uma cultura de aula de matemática. Boletim de Educação Matemática, Rio Claro, v. 28, n. 49, p. 875895, 2014.

CURI, E. A matemática e os professores dos anos iniciais. São Paulo: Musa Editora, 2005.

CURI, E. Práticas e reflexões de professras numa pesquisa longitudinal. Revista Brasileira de Estudos Pedagógicos, Brasília, v. 94, n. 237, p. 474-500, maio/ago. 2013.

CURY, F. G.; SOUZA, L. A. D.; SILVA, H. D. Narrativas: um olhar sobre o exercício historiográfico na Educação Matemática. Boletim de Educação Matemática, Rio Claro, v. 28, n. 49, p. 910-925, 2014.

GATTI, B. A.; NUNES, M. M. R. Formação de professores para o ensino fundamental: estudo de currículos das licenciaturas em pedagogia. São Paulo: Fundação Carlos Chagas/Departamento de Pesquisas Educacionais, 2009. (Coleção Textos FCC, 29).

KNIJNIK, G. A ordem do discurso da matemática escolar e jogos de linguagem de outras formas de vida. Perspectivas da Educação Matemática, Campo Grande, v. 10, n. 22, p. 45-64, 2017.

LINS, R. C. Por que discutir teoria do conhecimento é relevante para a Educação Matemática. In: BICUDO, M. A. V. (Org.). Perspectivas em educação matemática: concepções e perspectivas. São Paulo: Editora da UNESP, 1999. p. 75-94.

LINS, R. C. O modelo dos campos semânticos: estabelecimento e notas de teorizações. In: ANGELO, C. L. et al. (Org.). Modelo dos Campos Semânticos e Educação Matemática: 20 anos de história. São Paulo: Midiograf, 2012. p. 11-30.

NACARATO, A. M. A formação matemática das professoras das séries iniciais: a escrita de si como prática de formação. Boletim de Educação Matemática, Rio Claro, v. 23, n. 37, p. 905-930, 2010.

NACARATO, A. M.; MENGALI, B. L. D. S.; PASSOS, C. L. B. A matemática nos anos iniciais do ensino fundamental: tecendo fios do ensinar e do aprender. Belo Horizonte: Autêntica, 2009. 
(Coleção Tendências em Educação Matemática).

NACARATO, A. M.; PASSEGGI, M. D. C. Narrativas autobiográficas por futuras professoras: representações sobre a matemática escolar. Revista de Educação PUC-Campinas, Campinas, v. 18, n. 3, p. 287-299, 2013.

SILVA, C. R. D.; ALVES, S. L. M.; MIRANDA, I. F. Professores que vão ensinar matemática nos anos iniciais: educação matemática nos cursos de pedagogia. REVEMAT, Florianópolis, v. 8, n. 1, p. 266-283, 2013.

SILVA, G. H. G.; POWELL, A. B. Microagressões no ensino superior nas vias da educação matemática. Revista Latinoamericana de Etnomatemática, San Juan de Pasto, Colômbia, v. 9, n. 3, p. 44-76, 2016.

SILVA, V. C. D.; GARNICA, A. V. M. Mostruário de Práticas: considerações sobre a formação e a atuação de professores dos anos iniciais a partir das Feiras Catarinenses de Matemática. Boletim de Educação Matemática, Rio Claro, v. 29, n. 53, p. 909-935, 2015.

SKOVSMOSE, O. Um convite à educação matemática crítica. Tradução de Orlando de Andrade Figueiredo. Campinas: Papirus, 2014. (Coleção Perspectivas em Educação Matemática).

SOLÓRZANO, D. G.; CEJA, M.; YOSSO, T. J. Critical race theory, racial microaggressions, and campus racial climate: The experiences of African American college students. Journal of Negro Education, Washington, DC, v. 69, n. 1 - 2, p. 60 -73, 2000.

SOLÓRZANO, D. G.; YOSSO, T. J. Critical Race Methodology: Counter-Storytelling as an Analytical Framework for Education Research. Qualitative Inquiry, Thousand Oaks, v. 8, n. 1, p. 2344, Feb. 2002.

SUE, D. W. et al. Racial microaggressions in everyday life: implications for clinical practice. Am Psychol, Washington, DC, v. 62, n. 4, p. 271-86, may./jun. 2007.

UNIVERSIDADE FEDERAL DE ALFENAS. Projeto Pedagógico do curso de Pedagogia. Alfenas Instituto de Ciências Humanas, 2011. Disponível em: <http://www.unifal-mg.edu.br/graduacao/sys tem/files/imce/PPCcomaltera\%C3\%A7\%C3\%B5eseresolu\%C3\%A 7\%C3\%B5es - mai 2016.pdf>. Acesso em: 04 maio 2017.

Submetido em 05 de Setembro de 2017. Aprovado em 13 de Abril de 2018. 